\title{
LEGUME SEEDS AND CEREAL GRAINS' CAPACITY TO ACCUMULATE IRON WHILE SPROUTING IN ORDER TO OBTAIN FOOD FORTIFICANT*
}

\author{
Magdalena Zielińska-Dawidziak ${ }^{1 凶}$, Halina Staniek², Ewelina Król², \\ Dorota Piasecka-Kwiatkowska ${ }^{1}$, Tomasz Twardowski ${ }^{3}$ \\ ${ }^{1}$ Department of Food Biochemistry and Analysis, Poznań University of Life Sciences \\ Mazowiecka 48, 60-623 Poznań, Poland \\ ${ }^{2}$ Department of Human Nutrition and Hygiene, Poznań University of Life Sciences \\ Wojska Polskiego 31, 60-624 Poznań, Poland \\ ${ }^{3}$ Institute of Bioorganic Chemistry, Polish Academy of Sciences \\ Noskowskiego 12/14, 61-704 Poznań, Poland
}

\begin{abstract}
Background. Prepared sprouts, after culturing in a medium with an increased iron concentration, could become a beneficial food iron fortificant. However, the efficient iron accumulation depends on the plants genus, species and/or varieties. The aim of the study was to indicate the seeds or grains which accumulate iron most efficiently during the sprouting process.

Material and methods. Alfalfa, lentil, lupine and soybean seeds as well as wheat grains were sprouted in abiotic stress conditions induced by the excess of iron(II) in culture media. The tolerance of these plants to iron concentration and its accumulation in the material obtained (with FAAS method) were analyzed.

Results. The smallest tolerance was noted for lentil seeds and wheat grains. Other plants developed in $25 \mathrm{mM}$ solution of $\mathrm{FeSO}_{4}$. The highest accumulation of iron was observed in alfalfa sprouts. However, lupine and soybean seeds are the most recommended raw material for the production of the sprouts on an industrial scale.
\end{abstract}

Key words: legume seeds, iron accumulation, wheat grain, plant tolerance

\section{INTRODUCTION}

Iron is a trace heavy metal required by plants for their proper growth, because it is a part of important metalloproteins involved in some redox reactions, which take place during respiration, photosynthesis, oxidative stress protection and many other processes
(Hänsch and Mendel, 2009). Both deficiency and excess of iron in soil leads to a disturbance in plant development.

A high concentration of this heavy metal in the growth medium or soil causes oxidative damage to

\footnotetext{
* These experiments were carried out as a part of two projects: N312 029 31/2098 (supported by the Polish Ministry of Science and Higher Education) and POIG 01.01.02-00-061/09 ('New bioactive food with designed functional properties' conducted by the Poznań University of Life Sciences).

Special thanks to Sefar Ltd. (Poland) for mesh Sefar Petex 07-2000/45 blue used in seeds sprouting.

『mzd@up.poznan.pl, phone +48 61848 7344, fax +48 618487352
} 
cellular components (mainly lipids, proteins and nucleic acids) (Dietz et al., 1999) and may lead to the displacement of the correct metal ions in proteins' active sides (Nishida et al., 2012). The defense against excess of heavy metal ions, including iron, may be achieved by the avoidance strategy (extracellular precipitation, biosorption to cell walls, reduced uptake or increased efflux). The other strategy - tolerance - allows a plant to survive a high iron concentration by intracellular chelation by amino acids, glutathione and ligands such as metallothioneins, phytochelatins, ferritin or compartmentation within vacuoles (Assunção et al., 2003; Clemens 2006; Cobbett 2000; Hall, 2002; Nishida et al., 2012; Yadav 2010; Yang et al. 2005).

Plants developed various mechanisms of protection against both iron ions: ferrous - Fe(II) and ferric$\mathrm{Fe}(\mathrm{III})$. Moreover, these mechanisms are different for graminaceous and nongraminaceous plants. Graminaceous plants developed a strategy based on chelation of slightly soluble iron from the rhizsosphere, secreting iron-chelator phytosiderophore (such as mugineic acids) to the rhizosphere. Nongraminaceous monocots and dicots transport iron from the soil after the reduction of ferric ions $\mathrm{Fe}$ (III) to ferrous ion by ferric-chelate reductase. The molecules - transporters, chelators and enzymes - responsible for the transport have been recognized for these two mechanisms. Manipulation of these molecular components expression results in the plants' tolerance to an iron increase or deficiency in the soil and on their capacity to accumulate iron in the edible part (Kobayashi and Nishizawa, 2012).

Increasing the iron concentration in the growth medium of many plants would intensify its accumulation processes and plants could be forced to accumulate the metal ions in their cells. In that manner biofortification of edible plants may be achieved. Plants biofortified in iron may become promising an iron source to prevent iron deficiency anaemia, because in some plant species phyto-ferritin, which is of interest to nutritionists, is an important and dominating chelating iron organic compound (Theil, 2004; Zielińska-Dawidziak et al., 2012a; Zielińska-Dawidziak, 2015).

The significant restriction of this process occurs due to the limited tolerance of different plants to iron concentration in the growth medium and metal accumulation capacity. These parameters were studied in the present experiment on sprouting seeds or grains of the following plants: alfalfa, lentil, lupine, soybean and wheat.

\section{MATERIAL AND METHODS}

\section{Experimental material}

The following seeds and grains were used in the presented experiments:

- alfalfa seeds (Medicago sativa L.), Tula and Kometa varieties obtained from the Poznań Plant Breeding Ltd., Tulce, Poland

- lentil seeds (Lens culinaris) Tina and Anita varieties delivered by 'Spójnia' Plant Breeding Ltd., Nochowo, Poland

- lupine seeds of three species i.e. white lupine ( $L u$ pinus albus), Boros and Butan varieties, yellow lupine (Lupinus luteus) Lord, Paris and Mister varieties and blue lupine (Lupinus angustifolius), Zeus and Baron varieties obtained from the Smolice Plant Breeding in Przebędowo, Poland

- soybean seeds (Glycine max), Nawiko and Augusta varieties provided by the Department of Genetics and Plant Breeding, the Poznań University of Life Sciences, Poland

- wheat grains (Triticum aestivum L.), Bombona and Korweta variety obtained from the DANKO Plant Breeding Ltd., Choryń, Poland.

\section{Methods}

Seeds germination. The raw seeds/grains were disinfected for 15 min with $70 \%$ ethanol. The ethanol was washed away and experimental materials swelled for 6 hours in $0-25 \mathrm{mM}$ solutions of $\mathrm{FeSO}_{4}$. Sprouting was carried out for 7 days in respective $\mathrm{FeSO}_{4}$ solutions in special germination dishes placed in climatic chambers (Adaptis, Conviron, Germany), in the same temperature and light conditions. On the last day, the seeds were watered, dried in a stream of air until $8-10 \%$ moisture was obtained. Germination was also carried in $\mathrm{Fe}_{2}\left(\mathrm{SO}_{4}\right)_{3}$ solutions with the same concentrations.

Preparation of the anatomical parts of sprouts. Hull, radicle and seeds were separated manually from fresh sprouts and then dried in the conditions presented above.

Iron content determination. The samples were mineralized at $450^{\circ} \mathrm{C}$ to obtain a carbon-free white ash. Afterwards, the ash dissolved in $1 \mathrm{~N}$ nitric acid was filtered and analyzed for iron content using flame atomic absorption spectrometry with deuterium (Zeiss AAS-3, Jena) $(\lambda=248.3$, slit width of $0.15 \mathrm{~nm})$ (Tsalev, 1995). 
Statistical analysis. Statistical analyses were performed using Statistica 10.0. (StatSoft Inc., Tulsa, USA). All germinations were repeated nine times, while part separations and analyses of iron content were performed in triplicate. All the data were expressed as an average \pm standard deviation and were subjected to analysis of variance (ANOVA). In the case of significant differences, post-hoc analysis (Tukey's test) was performed to determine homogeneous groups.

\section{RESULTS AND DISCUSSION}

The use of sprouts biofortified in iron may be a promising way to increase iron content in food. However, the problem of this metal's toxicity has been observed for many years. Plants growing in iron-rich soil were degenerated, discolored and thus unattractive for consumers. Moreover, the correlation between the iron concentration in the soil and in cereal grains, legume seeds or other edible parts of plants (leaves or fruits) was far from linear (Lönnerdal, 2003).

It has been noted in many studies on the hyperaccumulation of heavy metal ions that root metal foraging is associated with high levels of tolerance to the toxic metal's presence in the soil/growth medium (Lönnerdal, 2003). The term 'tolerance level' in the present experiments represents the highest concentration of iron in media in which sprouts development was observed, even if radicl development was heavily limited. Simultaneously, the number of germinated seeds/grain had to be at least $80 \%$ of those germinated in distilled water. Lentil seeds and wheat grains revealed the lowest tolerance to the abiotic stress caused by the presence of ferrous ions in the medium; but lentil sprouts were better developed in $14 \mathrm{mM}$ of $\mathrm{FeSO}_{4}$ than wheat sprouts in $15 \mathrm{mM}$. Other seeds tolerated the $25 \mathrm{mM}$ of $\mathrm{FeSO}_{4}$ in the media. No differences in tolerance level between varieties of the same genus was noted in these experiments (Fig. 1).

The level of tolerance does not always determine the plants' capacity to accumulate iron, even if it is strongly correlated with both metal ions transporters and chelating compound expression in plants (eg. ferritin, which is the most interesting) (Lönnerdal, 2003). The accumulation of iron in the sprouts studied, obtained in four selected concentrations in the range of their tolerance, is presented on Figures 2-6.

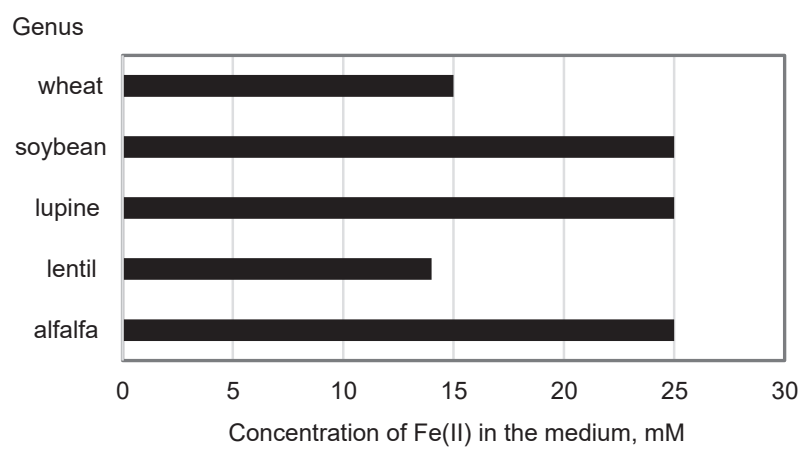

Fig. 1. The determined maximum tolerance level to the $\mathrm{FeSO}_{4}$ presence in growth media

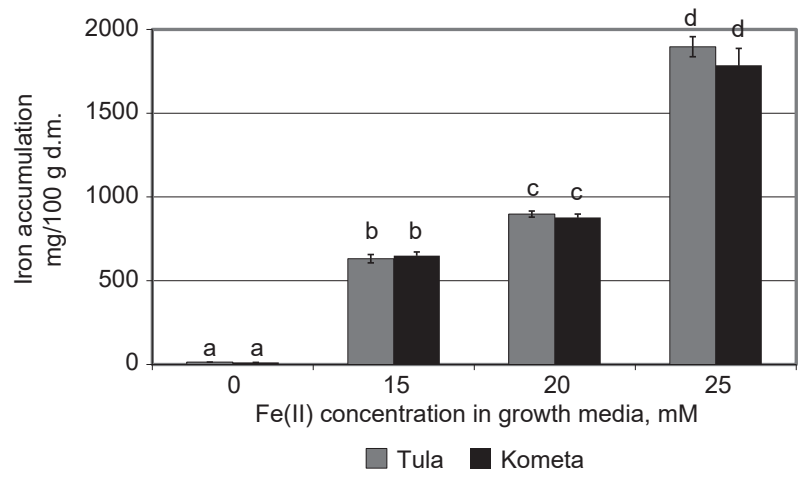

Fig. 2. The dependence of iron accumulation in alfalfa sprouts [mg/100 g d.m.] on variety and iron concentration in the culture media $[\mathrm{mM}]$. The bars denoted by various letters differ statistically significantly at the significance level $\alpha=0.05$

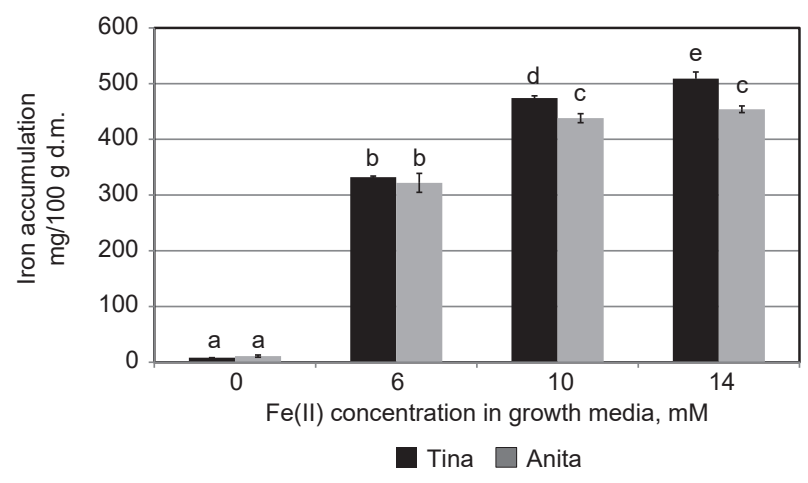

Fig. 3. The dependence of iron accumulation in lentil sprouts $[\mathrm{mg} / 100 \mathrm{~g} \mathrm{~d} . \mathrm{m}$.] on variety and iron concentration in the culture media $[\mathrm{mM}]$. The bars denoted by various letters differ statistically significantly at the significance level $\alpha=0.05$ 


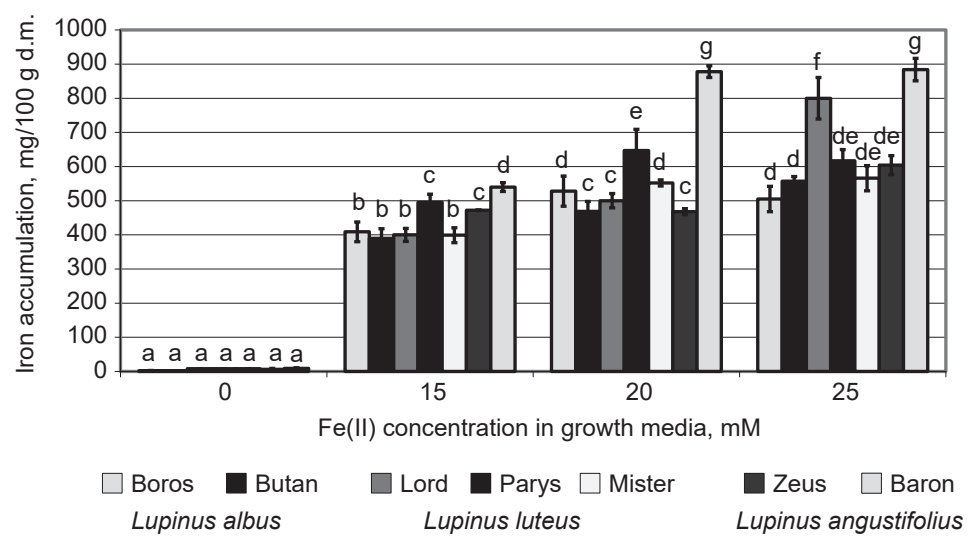

Fig. 4. The dependence of iron accumulation in lupine sprouts $[\mathrm{mg} / 100 \mathrm{~g}$ d.m.] on species, variety and iron concentration in the culture media $[\mathrm{mM}]$. The bars denoted by various letters differ statistically significantly at the significance level $\alpha=0.05$

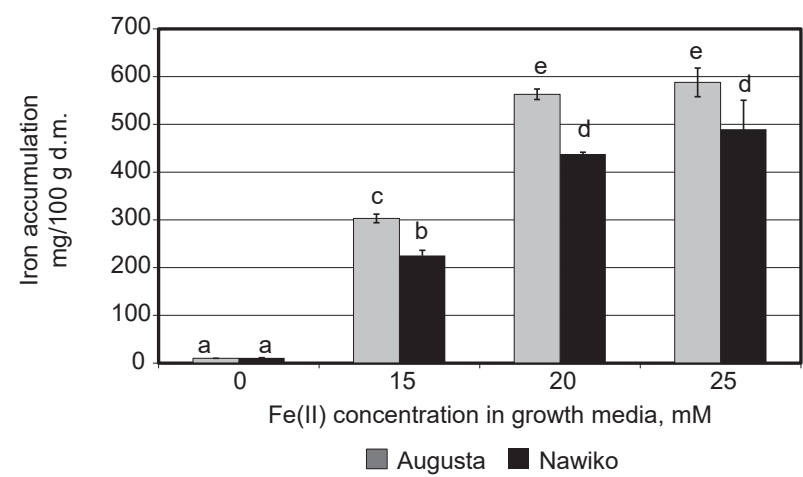

Fig. 5. The dependence of iron accumulation in soybean sprouts $[\mathrm{mg} / 100 \mathrm{~g}$ d.m.] on variety and iron concentration in the culture media $[\mathrm{mM}]$. The bars denoted by various letters differ statistically significantly at the significance level $\alpha=0.05$.

In the conditions mentioned, all sprouts accumulated much more iron than sprouts which were the reference sample, i.e. sprouts cultured in water $(0 \mathrm{mM}$ of $\mathrm{Fe}(\mathrm{II})$ in growth media). Among these plants, the greatest iron content was found for both varieties of alfalfa sprouts ( $\sim 1800 \mathrm{mg} / 100 \mathrm{~g}$ d.m.). However, despite such promising results, the possibility of using alfalfa sprouts on an industrial scale is not currently reasonable, because of the low level of alfalfa seed harvesting. Lentils accumulate the least iron among legume seeds $(\sim 550 \mathrm{mg} / 100 \mathrm{~g}$ d.m.), but from the solutions with low

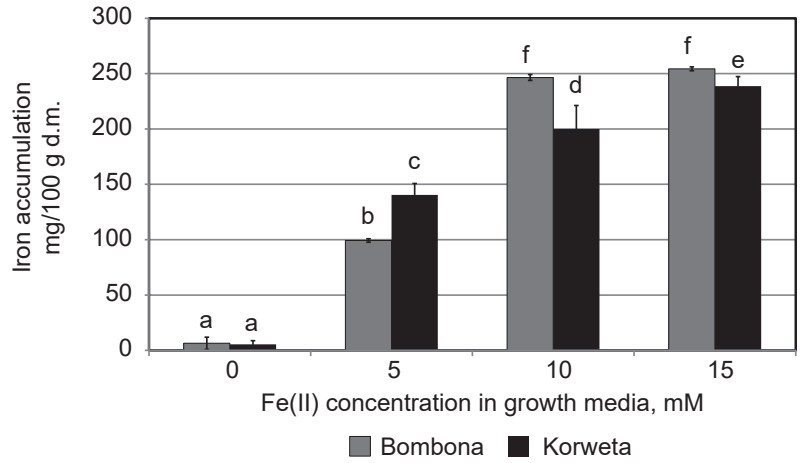

Fig. 6. The dependence of iron accumulation in wheat sprouts $[\mathrm{mg} / 100 \mathrm{~g} \mathrm{d.m}$.] on variety and iron concentration in the culture media $[\mathrm{mM}]$. The bars denoted by various letters differ statistically significantly at the significance level $\alpha=0.05$

iron concentrations $(14 \mathrm{mM})$, which could be profitable for their use on a commercial scale. Nevertheless, in a concentration of $15 \mathrm{mM}$ certain varieties of lupine (Parys and Baron) accumulated slightly less iron. Raw lentils (whole and not heat-treated) are difficult to obtain in Poland, because in Central and Eastern Europe their cultivation areas are limited, as opposed to Italy or France.

Wheat sprouts, obtained from the only cereal plant in this experiment, attained concentrations of even twice a little iron than lentil sprouts. This was 
Zielińska-Dawidziak, M., Staniek, H., Król, E., Piasecka-Kwiatkowska, D., Twardowski, T. (2016). Legume seeds and cereal grains' capacity to accumulate iron while sprouting in order to obtain food fortificant. Acta Sci. Pol. Technol. Aliment., 15(3), 333-338. DOI: 10.17306/J.AFS.2016.3.32

Table 1. Comparison of iron in anatomical parts of sprouts: seeds, hulls, radicles and whole sprouts of Lupinus albus (Boros var.), L. luteus (Lord var.) L. angustifolius (Baron var.) and G. max (Augusta var.).

\begin{tabular}{lcccc}
\hline \multirow{2}{*}{$\begin{array}{c}\text { Analyzed } \\
\text { material }\end{array}$} & \multicolumn{4}{c}{ Iron content, $\mathrm{mg} / 100 \mathrm{~g} \mathrm{~d}$.m. } \\
\cline { 2 - 5 } & Boros & Lord & Baron & Augusta \\
\hline Seed & $414.85 \pm 8.35 a$ & $460.07 \pm 13.17 a$ & $519.17 \pm 4.21 a$ & $503.23 \pm 5.36 a$ \\
Hull & $873.55 \pm 6.46 d$ & $1202.22 \pm 5.91 d$ & $851.30 \pm 15.10 c$ & $704.32 \pm 10.26 c$ \\
Radicle & $632.56 \pm 13.95 c$ & $825.64 \pm 53.30 c$ & $1003.63 \pm 3.23 d$ & $899.39 \pm 28.35 d$ \\
Sprouts (whole) & $567.21 \pm 14.95 b$ & $704.08 \pm 27.26 b$ & $655.28 \pm 4.05 b$ & $588.38 \pm 31.35 b$ \\
\hline
\end{tabular}

The values in the table (expressed as an average \pm standard deviation) marked in columns with various letters are significantly different $(\alpha=0.05)$.

expected, because the expression of iron chelators in cereal grains is lower than in legumes (Burton et al., 1998), and the low tolerance of these grains was proved in the present studies. Using wheat grains for food fortification could be considered in situations when the use of legumes is not possible (eg. in food dedicated for allergic individuals). It should be noted here that variety did not influence the accumulation as much as the genus and species.

However, a higher iron accumulation was also noted in sprouts obtained from smaller seeds. It became obvious when the iron concentration in anatomical parts of the sprouts was analyzed. Most iron was concentrated in hulls and radicle of the materials studied (Table 1). Therefore, the lower mass ratio of growing radicle and husk to seed, the smaller the iron content noted in the preparation.

Unfortunately, an attempt to replace Fe(II) with $\mathrm{Fe}(\mathrm{III})$ ions in the medium was completely unsuccessful. Acceptance of oxidized iron forms could significantly facilitate sprout preparation on an industrial scale, due to possible media oxidation, but $\mathrm{Fe}_{2}\left(\mathrm{SO}_{4}\right)_{3}$ totally inhibited sprouting.

A previous study also indicated that during the year of harvest, weather conditions influenced the seeds' quality and subsequent iron accumulation during sprouting (Zielińska-Dawidziak et al., 2012b). Thus, because the seeds studied came from various growing areas, the data obtained in other harvest years and from other areas may differ, but only slightly, from those presented here.

Sprouts prepared in the proposed manner may become an attractive food fortificant (Zielińska-
-Dawidziak et al., 2012a), because the amount of them which could be introduced into food products according to the EU requirements should be extremely small (European Commission, 2002). Moreover, if they were used as a powdered component during food production, their degeneration would be almost irrelevant. However, due to economic reasons, the desired genus, species and variety of those plants which accumulate iron the most efficiently should be indicated. The only raw materials, currently easily available on an adequate scale in our geographical region are soybean and lupine seeds, therefore these two genus seeds may be recommended as the best material for sprout preparation.

These experiments confirmed the significant impact of genus, species and variety on the iron-binding capacity of plants sprouting in the media containing $\mathrm{FeSO}_{4}$. The plants' tolerance to iron ion presence in the media depends particularly on the genus. Seeds with smaller thousand grain weight are usually desirable for sprout preparation.

Lupine and soybean seeds could be recommended for the preparation of sprouts for food fortification in Central and Eastern Europe countries, although in regions with high levels of lentil harvesting, this plant could be also considered for this purpose.

\section{REFERENCES}

Assunção, A. G. L., Schat, H., Aarts, M. G. M. (2003). Thlaspi caerulescens, an attractive model species to study heavy metal hyperaccumulation in plants. New Phytol., 159, 351-360. 
Burton, J. W., Harlow, C., Theil, E. C. (1998). Evidence for reutilization of nodule iron in soybean seed development. J. Plant Nutr., 21, 913-927.

Clemens, S. (2006). Toxic metal accumulation, responses to exposure and mechanisms of tolerance in plants. Biochimie, 88, 1707-1719.

Cobbett, C. S. (2000). Phytochelatins and their roles in heavy metal detoxification. Plant Physiol., 123, 825-832.

Dietz, K. J., Baier, M., Krämer, U. (1999). Free radicals and reactive oxygen species as mediators of heavy metal toxicity in plants. In: M. N. V. Prasad, J. Hagemeyer (Eds.), Heavy metal stress in plants (pp. 73-97). Berlin: Springer.

European Commission (2002). Food Supplements Directive (2002/46/EC). EUR-Lex 29, 490-497.

Hall, J. L. (2002). Cellular mechanisms for heavy metal detoxification and tolerance. J. Exp. Bot., 53, 1-11.

Hänsch, R., Mendel, R. R. (2009). Physiological functions of mineral micronutrients $(\mathrm{Cu}, \mathrm{Zn}, \mathrm{Mn}, \mathrm{Fe}, \mathrm{Ni}, \mathrm{Mo}, \mathrm{B}$, Cl). Curr. Opin. Plant Biol., 12, 259-266.

Kobayashi, T., Nishizawa, N. K. (2012). Iron uptake, translocation, and regulation in higher plants. Ann. Rev. Plant Biol., 63, 131-152.

Lönnerdal, B. (2003). Genetically modified plants for improved trace element nutrition. J. Nutr., 133, 490-1493.

Nishida, S., Aisu, A., Mizuno, T. (2012). Induction of IRT1 by the nickel-induced iron-deficient response in Arabidopsis. Plant Signal Behav., 7, 329-331.
Theil, E. C. (2004). Iron, ferritin, and nutrition. Ann. Rev. Nutr., 24, 327-343.

Tsalev, D. (1995). Iron. In: D. Tsalev (Ed.) Atomic absorption spectrometry in occupational and environmental healths practice: determination of individual elements (Vol II, pp. 111-119). Boca Raton: CRC Press.

Yadav, S. K. (2010). Heavy metals toxicity in plants: an overview on the role of glutathione and phytochelatins in heavy metal stress tolerance of plants. S. Afr. J. Bot., 76, 167-179.

Yang, X. E., Jin, X. F., Feng, Y., Islam, E. (2005). Molecular mechanisms and genetic basis of heavy metal tolerance/ hyperaccumulation in plants. J. Integr. Plant Biol., 47, 1025-1035.

Zielińska-Dawidziak, M. (2015). Plant ferritin - a source of iron to prevent its deficiency. Nutrients, 7, 1184-1201.

Zielińska-Dawidziak, M., Hertig, I., Piasecka-Kwiatkowska, D., Staniek, H., Nowak, K. W., Twardowski, T. (2012a). Study on iron availability from prepared soybean sprouts using an iron-deficient rat model. Food Chem., 135, 2622-2627.

Zielińska-Dawidziak, M., Nawracała, J., Piasecka-Kwiatkowska, D., Staniek, H., Król, E., Krejpcio, Z. (2012b). Effect of soybean seeds year harvest (Glycine max L. Merrill) on iron accumulation from $\mathrm{FeSO}_{4}$ solutions. Fragm. Agron., 29, 183-193. 